\title{
Promoter-specific regulation of PPARGC1A gene expression in human skeletal muscle
}

\author{
Daniil V Popov ${ }^{1,2}$, Evgeny A Lysenko', Tatiana F Vepkhvadze', Nadia S Kurochkina', \\ Pavel A Maknovskii ${ }^{3}$ and Olga L Vinogradova ${ }^{1,2}$ \\ 'Laboratory of Exercise Physiology, Institute of Biomedical Problems, Russian Academy of Sciences, \\ Khoroshevskoye shosse, 76A, Moscow 123007, Russia \\ ${ }^{2}$ Faculty of Fundamental Medicine, M.V. Lomonosov Moscow State University, Lomonosovskiy prospect, \\ 31-5, Moscow 119192, Russia \\ ${ }^{3}$ Department of Genetics, Faculty of Biology, M.V. Lomonosov Moscow State University, Leninskie Gory, \\ 1-12, Moscow 119991, Russia
}

\author{
Correspondence \\ should be addressed \\ to D V Popov \\ Email \\ danil-popov@yandex.ru
}

\begin{abstract}
The goal of this study was to identify unknown transcription start sites of the PPARGC1A $(P G C-1 \alpha)$ gene in human skeletal muscle and investigate the promoter-specific regulation of $P G C-1 \alpha$ gene expression in human skeletal muscle. Ten amateur endurance-trained athletes performed high- and low-intensity exercise sessions $\left(70 \mathrm{~min}, 70 \%\right.$ or $\left.50 \% \dot{V}_{\mathrm{O}_{2 \max }}\right)$. High-throughput RNA sequencing and exon-exon junction mapping were applied to analyse muscle samples obtained at rest and after exercise. PGC-1 $\alpha$ promoter-specific expression and activation of regulators of PGC-1 $\alpha$ gene expression (AMPK, p38 MAPK, CaMKII, PKA and CREB1) after exercise were evaluated using qPCR and western blot. Our study has demonstrated that during post-exercise recovery, human skeletal muscle expresses the $P G C-1 \alpha$ gene via two promoters only. As previously described, the additional exon 7 a that contains a stop codon was found in all samples. Importantly, only minor levels of other splice site variants were found (and not in all samples). Constitutive expression $P G C-1 \alpha$ gene occurs via the canonical promoter, independent of exercise intensity and exercise-induced increase of AMPK ${ }^{\text {Thr } 172}$ phosphorylation level. Expression of PGC-1 $\alpha$ gene via the alternative promoter is increased of two orders after exercise. This post-exercise expression is highly dependent on the intensity of exercise. There is an apparent association between expression via the alternative promoter and activation of CREB1.
\end{abstract}

\section{Key Words \\ - skeletal muscle \\ - PGC-1 $\alpha$ \\ - alternative promoter \\ - exercise}

Journal of Molecular Endocrinology (2015) 55, 159-168

\section{Introduction}

Peroxisome proliferator-activated receptor gamma coactivator 1-alpha (PGC-1 $\alpha$ ) is a key regulator of mitochondrial biogenesis, angiogenesis, as well as fat and carbohydrate metabolism in skeletal muscle (Olesen et al. 2010, Popov et al. 2015). Mouse and human skeletal muscle expresses several PGC-1 $\alpha$ (PPARGC1A) gene isoforms originating from the canonical (PGC-1 $\alpha-a$ mRNA) and alternative (PGC-1 $\alpha-b$ and $P G C-1 \alpha-c$ mRNA) promoters (Miura et al. 2008, Yoshioka et al. 2009). Alternative splicing at the intron between exons 6 and 7 can generate N-truncated (NT) PGC- $1 \alpha$ isoforms (Zhang et al. 2009), which possess unique properties, different to those of

Published by Bioscientifica Ltd 
full-length isoforms (Thom et al. 2014). Thus, the $P G C-1 \alpha$ gene has the potential to produce at least six transcripts (Chang et al. 2012). However, another study in mouse skeletal muscle found only two previously described isoforms (PGC-1 $\alpha-a$ and NT-PGC- $1 \alpha-b$ mRNAs), as well as two additional isoforms (PGC- $1 \alpha-2$ and $P G C-1 \alpha-3$ mRNAs) with multiple splicing between exons (Ruas et al. 2012). Other tissue-specific promoters and isoforms have been described in human nervous tissue (Soyal et al. 2012) and liver (Felder et al. 2011).

Acute endurance exercise leads to increased $P G C-1 \alpha$ gene expression in skeletal muscle. AMP-activated protein kinase (AMPK), p38 mitogen-activated protein kinase (p38 MAPK), and $\mathrm{Ca}^{2+} /$ calmodulin-dependent protein kinase (CaMKII) appear to be important for regulation of activityinduced $P G C-1 \alpha$ gene expression from the canonical promoter (Zhang et al. 2014). Several groups (Norrbom et al. 2011, Ydfors et al. 2013, Popov et al. 2014) have shown that in human skeletal muscle, acute exercise induces $P G C-1 \alpha$ gene expression, mainly via the alternative promoter. Based on studies in rodent skeletal muscle, it was proposed that activation of exercise-induced expression via the alternative promoter is regulated by the beta- 2 adrenergic receptor-protein kinase A (PKA)cAMP response element-binding protein (CREB1) signalling pathway (Chinsomboon et al. 2009, Tadaishi et al. 2011). Human myoblast (Norrbom et al. 2011) and mouse (Wen et al. 2014) studies showed that AMPK plays a role in the regulation of expression via the alternative promoter. However, another myoblast study (Yoshioka et al. 2009) and a study in isolated rat muscle (Tadaishi et al. 2011) did not confirm this finding.

Taken together, these findings indicate that alternative splicing of the $P G C-1 \alpha$ gene has a strong influence on the properties of PGC- $1 \alpha$ proteins, and that different signalling pathways activate the expression of the $P G C-1 \alpha$ gene via different promoters. Investigations on the regulation of $P G C-1 \alpha$ gene expression in human skeletal muscle have not been sufficient. The goal of this study was to identify unknown transcription start sites of the $P G C-1 \alpha$ gene in human skeletal muscle, and to determine if mRNA splice site variants exist at rest and after acute exercise. For this purpose, high-throughput RNA sequencing and exonexon junction mapping were applied to analyse samples obtained at rest and after exercise. The second goal was to investigate the promoter-specific regulation of $P G C-1 \alpha$ gene expression in human skeletal muscle. For this purpose, we evaluated $P G C-1 \alpha$ promoter-specific expression and activation of regulators of $P G C-1 \alpha$ gene expression (AMPK, p38 MAPK, CaMKII, and CREB1) after aerobic exercise at different intensities (50 and 70\% $\left.\dot{V}_{\mathrm{O}_{2 \max }}\right)$. PGC-1a mRNA expression in untrained subjects is higher after the first exercise session than after subsequent sessions (Perry et al. 2010). For this reason, the regulation of $P G C-1 a$ expression was investigated in skeletal muscle of subjects adapted to endurance training.

\section{Materials and methods}

\section{Ethical approval}

The study was approved by the Human Ethics Committee of the Institute of Biomedical Problems. The study complied with the guidelines set forth in the Declaration of Helsinki. All the participants provided their written consent to participate in this study.

\section{Initial study}

Ten amateur endurance-trained athletes (runners, cyclists, and cross country skiers with a median weight of $70 \mathrm{~kg}$ (interquartile range: $67-73 \mathrm{~kg}$ ) and $\dot{V}_{\mathrm{O}_{2 \max }}$ of $61 \mathrm{ml} / \mathrm{min}$ per kg body weight (interquartile range: $58-62 \mathrm{ml} / \mathrm{min}$ per $\mathrm{kg}$ body weight)) participated in this study. During the first two visits to the laboratory, subjects were familiarized with the test procedures and completed an incremental ramp test on an Ergoselect 200 electromagnetic bicycle ergometer (Ergoline, Bitz, Germany). Initial load, load increment, and revolution rate were $0 \mathrm{~W}, 15 \mathrm{~W} / \mathrm{min}$, and 60-70 r.p.m. respectively. Each subject exercised until exhaustion. A revolution rate that slowed to 50 r.p.m. and a respiratory exchange ratio that increased to more than 1.1 were indicative of exhaustion. The pulmonary oxygen uptake rate $\left(\dot{V}_{2}\right)$ was measured at consecutive 15-s intervals, using an AMIS 2000 medical mass-spectrometer (Innovision, Odense, Denmark) with a mixing chamber. The highest $\dot{V} \mathrm{O}_{2}$ value for $30 \mathrm{~s}$ was taken as $\dot{V} \mathrm{O}_{2 \max }$.

\section{Primary study}

Each subject participated in high- and low-intensity exercise sessions (HE and LE), in random order, separated by 1 week. All subjects were instructed to refrain from vigorous aerobic and strength exercises for 1 week before the test, and from all exercise $36 \mathrm{~h}$ before. Subjects arrived at the laboratory at $0900 \mathrm{~h}$ and had a standardized breakfast (3624 kJ, $24 \mathrm{~g}$ protein, $157 \mathrm{~g}$ carbohydrate, and $15 \mathrm{~g}$ lipid). The cycling session started $1 \mathrm{~h} 45 \mathrm{~min}$ after breakfast, and consisted of a warm-up (5 min, 50\% $\dot{V}_{\mathrm{o}_{2 \max }}$ ) and exercise session (65 min, $70 \%$ or $50 \% \dot{V}_{\mathrm{o}_{2 \max }}$

Published by Bioscientifica Ltd. 
for HE and LE respectively). Two hours after the exercise session, the subjects had a standardized lunch $(3714 \mathrm{~kJ}$, $45 \mathrm{~g}$ protein, $183 \mathrm{~g}$ carbohydrate, and $27 \mathrm{~g}$ lipid). Capillary blood was drawn from the fingertip prior to, and at 20, 40, and $60 \mathrm{~min}$ after initiation of exercise. Lactate concentration was determined using a Super GL easy analyzer (Dr Mueller Geraetebau, Freital, Germany). The venous blood was drawn from the $v$. intermedia cubiti using catheter prior to, and at 30, 60, and $90 \mathrm{~min}$ after the exercise session. The plasma concentration of cortisol was evaluated using an ELISA-Cortisol kit (Immunotek, Moscow, Russia). Biopsies from the $m$. vastus lateralis were taken using the microbiopsy technique (Hayot et al. 2005) prior to exercise, and at $2 \mathrm{~min}, 4 \mathrm{~h}$, and $8 \mathrm{~h}$ after under local anaesthesia ( $2 \mathrm{ml}$ of $2 \%$ lidocaine). The muscle samples were quickly blotted with a gauze to remove superficial blood, frozen in liquid nitrogen, and stored at $-80^{\circ} \mathrm{C}$ until analysis. The first biopsy was taken $15 \mathrm{~cm}$ proximal to the condylus lateralis ossis femoris. Subsequent biopsies were taken $2 \mathrm{~cm}$ proximal to the previous one. The biopsy samples were taken on different days from different legs.

\section{RNA extraction}

Frozen samples ( $\sim 20 \mathrm{mg}$ ) were sectioned at $20 \mu \mathrm{m}$, using a Leica ultratome (Leica Microsystems, Wetzlar, Germany). RNA was extracted from samples using the RNeasy Mini Kit (Qiagen, Hilden, Germany). RNA concentration and purity were measured on a NanoDrop 2000 spectrophotometer (Thermo Scientific, Wilmington, USA). After DNase treatment (Fermentas, Vilnius, Lithuania), an MMLV RT kit (Evrogen, Moscow, Russia) was used to obtain cDNAs with $1 \mu \mathrm{g}$ of total RNA.

\section{RNA-seq}

Total RNA was taken from samples of two subjects for RNA sequencing prior to and at 4 and $8 \mathrm{~h}$ after exercise (six samples in total). The quality of RNA was checked for each sample by capillary electrophoresis, using an Agilent 2100 Bioanalyzer. All samples had an RNA integrity number $>9$. Library preparation was performed using the TruSeq RNA sample kit v2 (Illumina). Before sequencing, library concentration was assessed using a Qubit fluorimeter (Invitrogen) and by real-time PCR (primers: I-qPCR-1.1 AATGATACGGCGACCACCGAGAT and I-qPCR-2.1 CAAGCAGAAGACGGCATACGA). Libraries were diluted to $2300 \mathrm{~h}$ and sequenced on an Illumina HiSDefault 2000 instrument with a read length of 50 base pairs. Quality control and trimming were performed using CLC
Genomics Workbench 6.5.1. High-quality reads were mapped to reference human genome GRCh37 and exonexon junctions were identified using Tophat2 (v2.0.13) (mapping parameters: maximum of two mismatches, only uniquely mapped reads were allowed). Reads were counted for known exons of each gene using HTsDefault (v0.6.1). Total gene reads were considered as a measure of gene expression level. Exon-exon junction mappings and the total number of reads covering an exon-exon junction were visualized by the IGV tool (Thorvaldsdottir et al. 2013). To analyse differential gene expression, the $\mathrm{R}$ package DESeq method was used (Anders \& Huber 2010).

\section{Real-time PCR}

Real-time PCR was performed using the Rotor-Gene Q cycler (Qiagen). The annealing temperature was optimized for each primer. The thermal profile included an initial heat-denaturing step at $95^{\circ} \mathrm{C}$ for $5 \mathrm{~min}$, followed by 45 cycles of denaturation at $95^{\circ} \mathrm{C}$ for $15 \mathrm{~s}$, annealing $\left(56-60{ }^{\circ} \mathrm{C}\right)$ for $30 \mathrm{~s}$, and extension at $72^{\circ} \mathrm{C}$ for $30 \mathrm{~s}$. Amplified genes were quantified by fluorescence using the EvaGreen master mix (Syntol, Moscow, Russia). The specificity of the amplification was monitored by analysis of melting curves and agarose gel (1\%) electrophoresis. Each sample was run in triplicate, and a non-template control was included in each run. Target gene mRNA expression levels were calculated by the efficiencycorrected $\Delta \mathrm{Ct}$ method, as $\left(1+E_{\text {ref }}\right)^{C t \text { ref }} /\left(1+E_{\text {tar }}\right)^{\text {Ct tar }}$, where $C t$ is the threshold cycle and $E$ is the PCR efficiency. PCR efficiency was calculated using standard curves corresponding to target and reference genes (RPLPO, $G A P D H)$. Expression of the $P G C-1 \alpha$ gene from the canonical and alternative promoters was evaluated using primers aligned to exons $1 \mathrm{a}$ and 2 , and exons $1 \mathrm{~b}$ and 2 respectively. The total $P G C-1 \alpha$ gene expression was evaluated using primer pairs to exon 2 (common for all transcripts). The primer sequences are shown in Table 1.

\section{Western blot}

Frozen samples ( $\sim 10 \mathrm{mg}$ ) were sectioned at $20 \mu \mathrm{m}$, using a Leica ultratome (Leica Microsystems) and homogenized in ice-cold RIPA buffer containing protease and phosphatase inhibitors $(50 \mathrm{mM}$-glycerophosphatase, $50 \mathrm{mM} \mathrm{NaF}$, $1 \mathrm{mM} \mathrm{Na} \mathrm{VO}_{4}, 20 \mu \mathrm{g} / \mathrm{ml}$ aprotinin, $50 \mu \mathrm{g} / \mathrm{ml}$ leupeptin, $20 \mu \mathrm{g} / \mathrm{ml}$ pepstatin, and $1 \mathrm{mM}$ PMSF). Samples were then centrifuged for $10 \mathrm{~min}$ at $10000 \times \mathbf{g}$ at $4{ }^{\circ} \mathrm{C}$. Protein content was analysed by bicinchoninic acid (BCA) assay. Samples were mixed with Laemmli buffer (20 $\mu \mathrm{g}$ protein per lane),

Published by Bioscientifica Ltd 
Table 1 Primers used in this study

\begin{tabular}{lll}
\hline Transcript & \begin{tabular}{l} 
Strand \\
\cline { 1 - 2 } PGC-1 $\alpha$ exon 1a-derived
\end{tabular} & $\begin{array}{l}\text { Forward } \\
\text { Reverse }\end{array}$ \\
PGC-1 $\alpha$ exon 1b-derived & $\begin{array}{l}\text { Forward } \\
\text { Reverse }\end{array}$ \\
Total PGC-1 $\alpha$ & $\begin{array}{l}\text { Forward } \\
\text { Reverse }\end{array}$ \\
NR4A3 & $\begin{array}{l}\text { Forward } \\
\text { Reverse }\end{array}$ \\
MAFF & Forward \\
& Reverse \\
SIK1 & Forward \\
RPLP0 & Reverse \\
& Forward \\
GAPDH & Reverse \\
& Forward \\
Reverse
\end{tabular}

\begin{tabular}{l}
\hline Sequence, 5'-3' \\
\hline ATGGAGTGACATCGAGTGTGCT \\
GAGTCCACCCAGAAAGCTGT \\
ATGGAGTGACATCGAGTGTGCT \\
AGTCCACCCAGAAAGCTGTCT \\
CAGCCTCTTTGCCCAGATCTT \\
TCACTGCACCACTTGAGTCCAC \\
CATCGGTTTCGACGTCTCTTGT \\
CACTACGGCGTGCGAACCT \\
CCAAACCCTCCCAGGATTCAA \\
GGGGCATCTCTTCAGTGCAA \\
AGAGGACGGTGGAGTCACTG \\
CGCACTGGGCATTCCGATA \\
CACTGAGATCAGGGACATGTTG \\
CTTCACATGGGGCAATGG \\
CAAGGTCATCCATGACAACTTTG \\
GTCCACCACCCTGTTGCTGTAG
\end{tabular}

Product size (bp)

127

156

101

125

88

102

77

496

PGC-1 $\alpha$, peroxisome proliferator-activated receptor gamma, coactivator 1 alpha; NR4A3, nuclear receptor subfamily 4, group A, member 3; MAFF, v-maf avian musculoaponeurotic fibrosarcoma oncogene homolog F; SIK1, salt-inducible kinase 1; RPLP0, ribosomal protein, large, P0; GAPDH, glyceraldehyde3-phosphate dehydrogenase.

loaded onto a 10\% T polyacrylamide gel, and electrophoresis was performed in the Mini-PROTEAN Tetra cell system (Bio-Rad) at $20 \mathrm{~mA}$ per gel. The proteins were transferred onto nitrocellulose membranes using the Mini Trans-Blot system (Bio-Rad) in Towbin buffer for $3 \mathrm{~h}$ at $300 \mathrm{~mA}$. Membranes were stained with Ponceau $S$ to verify consistent loading of proteins, followed by washing and incubation in 5\% non-fat dry milk for $1 \mathrm{~h}$. Membranes were then incubated with anti-phospho-PKA Substrase (1:4000; Cell Signaling, Danvers, MA, USA), anti-phospho-AMP$\mathrm{K} \alpha 1 / 2^{\text {Thr172 }}$ (1:200; Santa Cruz Biotechnology, Dallas, TX, USA), anti-phospho-ACC ${ }^{\text {Ser222 }}$ (1:1000), anti-phospho-p38 MAPK $^{\text {Thr180/Tyr182 }}$ (1:500), anti-phospho-CaMKII ${ }^{\text {Thr286 }}$ (1:2500), anti-phospho-CREB1 $1^{\operatorname{Ser} 133}(1: 500)$, or antiGAPDH (1:2500; all Abcam) overnight at $4{ }^{\circ} \mathrm{C}$. The next day, membranes were incubated with anti-rabbit secondary antibody (Cell Signaling) for $1 \mathrm{~h}$. After each step, membranes were washed with PBS-Tween 20 (three times for 5 min each). Finally, membranes were incubated with ECL substrate (Bio-Rad), and luminescent signals captured using a ChemiDoc Imaging System (Bio-Rad). All data are expressed as the ratio of phosphorylated protein to GAPDH.

\section{Statistical analysis}

Sample volumes were small with non-normal data distributions, and thus the data are expressed as median and interquartile range. The Wilcoxon matched pairs signedrank test was used to compare repeated measurements. The relation between samples was evaluated by the Spearman rank correlation test. Level of significance was set at $P \leq 0.05$.

\section{Results}

Workloads for HE and LE were $3.2(2.9-3.3)$ and 2.4 (2.22.5) $\mathrm{W} / \mathrm{kg}$ body weight respectively. In contrast to LE, HE induced a pronounced metabolic response. Blood lactate level reached $4.3(3.9-5.4) \mathrm{mM}(P<0.01$, initial level was 2.3 (1.8-2.6) $\mathrm{mM}$ ) after the first $20 \mathrm{~min}$ of HE, and then did not change until termination of exercise (Fig. 1A). Blood cortisol level was elevated 1.4-fold after $30 \mathrm{~min}$ of termination of HE (from 295 (245-351) to 417 (364-567) nM, $P<0.05$, Fig. 1B)). On the other hand, both lactate level during LE and post-LE cortisol level demonstrated small decreases (from $1.9(1.7-2.2)$ to $1.2(1.1-1.6) \mathrm{mM}$, $P<0.01$ and from 335 (303-378) to 302 (208 to 327) nM, $P<0.01$, for lactate and cortisol respectively) and significantly differed $(P<0.01)$ between $\mathrm{HE}$ and $\mathrm{LE}$ (Fig. 1A and B).

Exon-exon junction mapping showed that at rest, $P G C-1 \alpha$ was expressed via the canonical promoter only (exon 1a-derived mRNA). HE induced expression from both the canonical and alternative promoter (exon 1bderived mRNA) (Fig. 2A). The alternative promotor was located $\sim 14 \mathrm{~kb}$ upstream of the canonical promoter, consistent with previous studies (Miura et al. 2008, Yoshioka et al. 2009). Exon 1c-derived mRNA was not detected in the post-exercise period. This observation is in agreement with our previous qPCR study, which showed very low post-exercise expression level of the exon 1c-derived $P G C-1 \alpha$ mRNA in human skeletal muscle (Popov et al. 2014). No other transcription start sites were found (Fig. 2A). As previously described

Published by Bioscientifica Ltd 

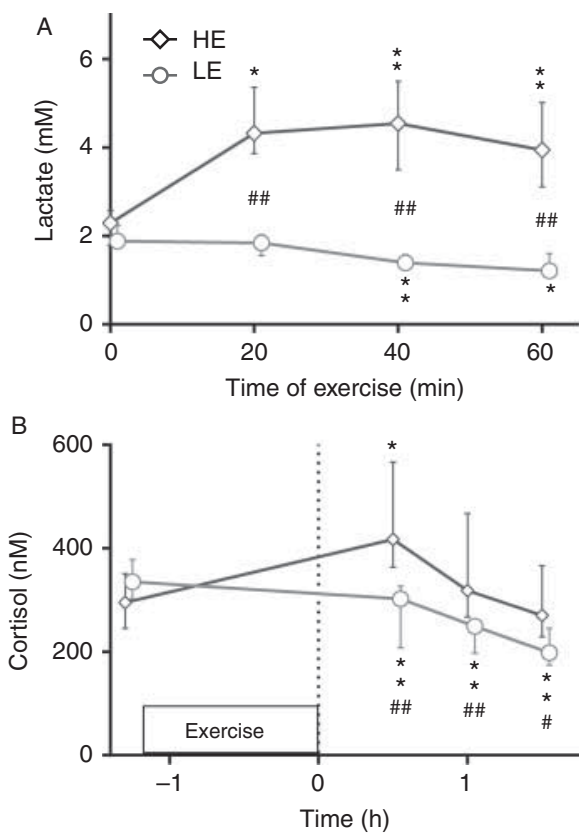

\section{Figure 1}

(A) The lactate in capillary blood before and during 70-min high- and lowintensity cycling bouts ( $70 \%$ and $50 \% \dot{V}_{\mathrm{O}_{2 \max }}$ respectively). (B) The plasma cortisol level before and after exercise bouts. * and ** different from the initial level $(P<0.05$ and $P<0.01$, respectively); \# and \#\# different between intensities $(P<0.05$ and $P<0.01$ respectively). Each value represents the median and interquartile range.

(Chang et al. 2012), the additional exon 7a that contains a stop codon was found in all samples (Fig. 2B). For other splice site variants, only low levels were detected (and not in all samples).
Quantitative PCR revealed that, at rest, $P G C-1 \alpha$ expression from the canonical promoter was significantly higher than for the alternative promoter. The exerciseinduced increase in $P G C-1 \alpha$ expression via the canonical promoter was small (1.3-fold and $P<0.05$ for both LE and HE) and did not depend on exercise intensity (Fig. 3B). The expression of $P G C-1 \alpha-b$ mRNA from the alternative promoter increased after both HE (471-fold, $P<0.01)$ and LE (101-fold, $P<0.01$; Fig. 3C). Post-exercise $P G C-1 \alpha-b$ mRNA expression was highly dependent on exercise intensity and reached a level threefold greater than for $P G C-1 \alpha-a$ mRNA, i.e. the increase of expression $P G C-1 a$ via alternative promoters contributes to the increase of total $P G C$ - $1 a$ mRNA to a greater extent than via canonical promoter. The total $P G C-1 \alpha$ gene expression increased by 5.3- $(P<0.01)$ and 2.3-fold $(P<0.05)$ after HE and LE respectively (Fig. 3A).

Phosphorylation levels of p38 MAPK $^{\text {Thr180/Tyr182 and }}$ CaMKII ${ }^{\text {Thr286 }}$ did not change immediately after both LE and HE sessions (Fig. 4B and C). The phosphorylation level of $\mathrm{AMPK}^{\mathrm{Thr} 172}$ was increased only after HE (1.4-fold, $P<0.01$, Fig. 4D). The substrate for AMPK, ACC $^{\text {Ser222, }}$, showed respective increases in phosphorylation levels (i.e. a marker of AMPK activity) of 4.0- and 2.8-fold, after HE and LE sessions $(P<0.05$ for both, Fig. 4E). The level of phospho-PKA substrates (i.e. a marker of PKA activity) did not change after both HE and LE (Fig. 4F). The CREB1 ${ }^{\text {Ser133 }}$ phosphorylation level increased $(1.4$-fold, $P<0.05)$ after HE only. Post-exercise phosphorylation level was higher for HE $(P<0.05)$ compared with LE (Fig. 4G).

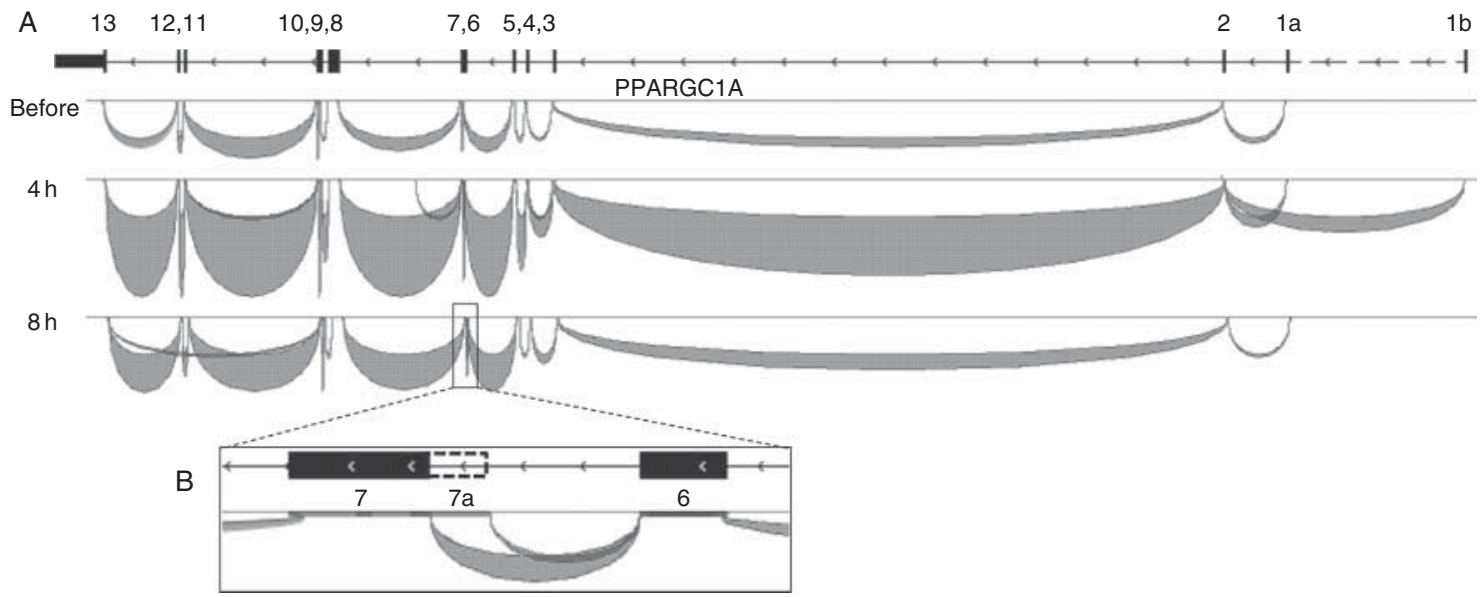

\section{Figure 2}

(A) Scheme of exons (vertical line) of the PGC-1a gene. Arches depict reads spanning an exon-exon boundary in $m$. vastus lateralis before, 4 and $8 \mathrm{~h}$ after acute high-intensity $\left(70 \% \dot{V}_{\mathrm{O}_{2 \max }}\right)$ cycling bout. Thickness of each arch reflects amount of the reads. At rest, the $P G C-1 \alpha$ is expressed via canonical promoter (exon 1a-derived mRNA) only. The exercise induces expression via both canonical and alternative (exon 1b-derived mRNA) promoters. (B) The additional exon 7a containing stop codon, which have been found in all samples. Only minor levels of other splice site variants (for instance, exons 10 to 13 junction at $8 \mathrm{~h}$ of recovery) were found (and not in all samples).

Published by Bioscientifica Ltd. 

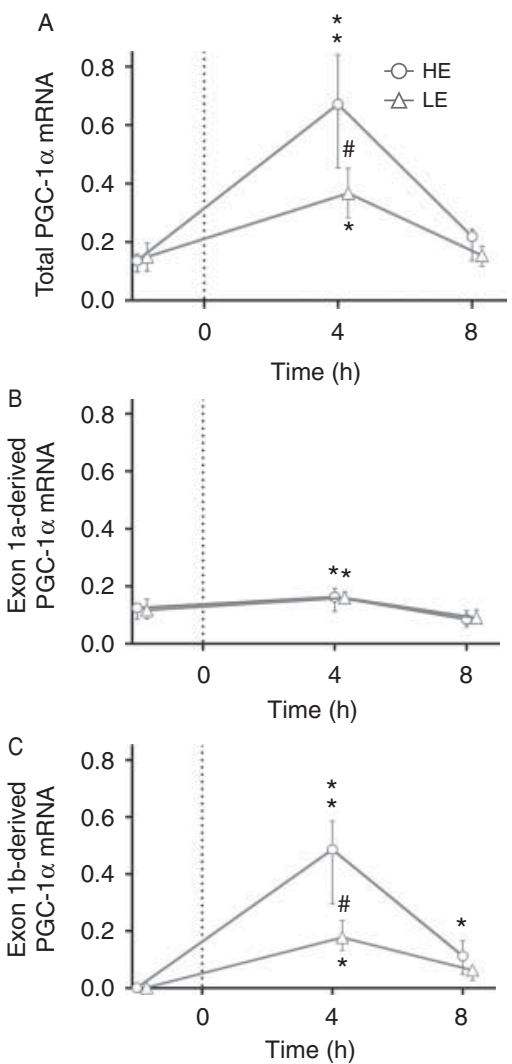

Figure 3

The total PGC-1a gene expression (A) and PGC-1a gene expression via (B) canonical (exon 1a-derived mRNA) and (C) alternative (exon 1b-derived mRNA) promoters in $m$. vastus lateralis before, $4 \mathrm{~h}$ and $8 \mathrm{~h}$ after acute high- and low-intensity cycling bouts ( $70 \%$ and $50 \% \dot{V}_{2} \mathrm{O}_{\text {max }}$, respectively). $0 \mathrm{~h}$ - the termination of exercise. * and ** different from the initial level $(P<0.05$ and $P<0.01$ respectively); \# different between intensities $(P<0.05)$. Each value represents the median and interquartile range.

High-throughput RNA-seq analysis revealed an increase in CREB1-dependent gene expression at 4 and $8 \mathrm{~h}$ after termination of exercise. This was in contrast to another potential transcriptional regulator of $P G C-1 \alpha$ gene expression that acts via the canonical promoter - myocyte enhancer factor 2 (MEF2C) (Fig. 5A). These findings were confirmed by qPCR (Fig. 5B, C, and D); the exerciseinduced expression of CREB1-dependent genes NR4A3, $M A F F$, and SIK1 at $4 \mathrm{~h}$ after termination of exercise was dependent on exercise intensity $(r=0.48 ; P=0.06, r=0.54$; $P<0.05$ and $r=0.6 ; P<0.05$ respectively). The comparison of mean gene expression data (PGC-1a, NR4A3, MAFF, and SIK1) with individual data of subjects 1 and 5 (samples involved in RNA sequencing) are shown in Supplementary Fig. 1, see section on supplementary data given at the end of this article.

The workload was correlated with expression of $P G C$ $1 \alpha-b$ mRNA from the alternative promoter at $4 \mathrm{~h}$ after

termination of exercise $(r=0.6 ; P<0.05)$, as well as with post-exercise phosphorylation level of $\mathrm{AMPK}^{\mathrm{Thr} 172}$ $(r=0.79 ; P<0.001)$. There was also a tendency toward significant correlation between the workload and phosphorylation level of CREB1 ${ }^{\mathrm{Ser} 133}(r=0.39 ; P=0.11)$.

\section{Discussion}

Exon-exon junction mappings have confirmed that in human skeletal muscle, the $P G C-1 \alpha$ gene is expressed via

A

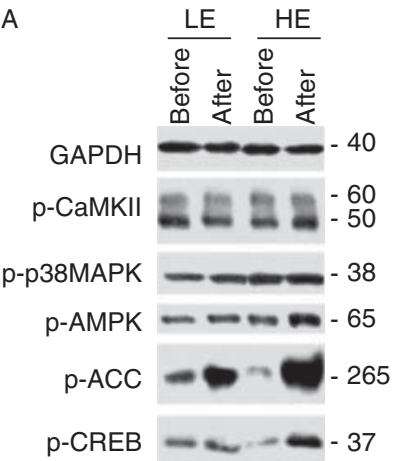

B

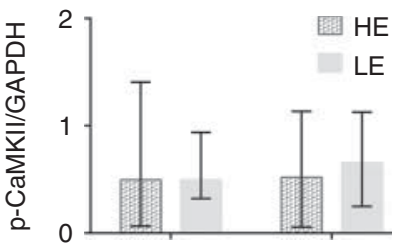

$\mathrm{D}$

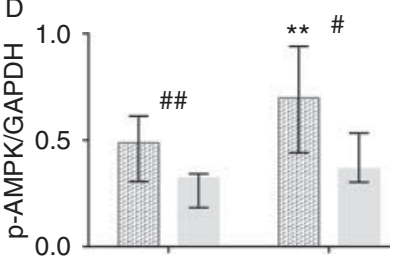

$\mathrm{F}$

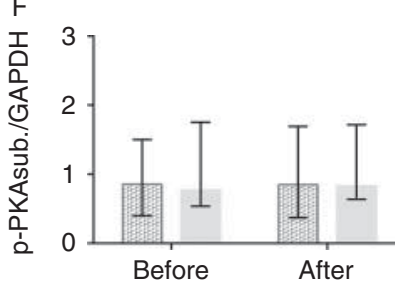

$\frac{\mathrm{LE}}{\frac{H E}{\Phi}} \frac{\mathrm{HE}}{\frac{0}{0}}$
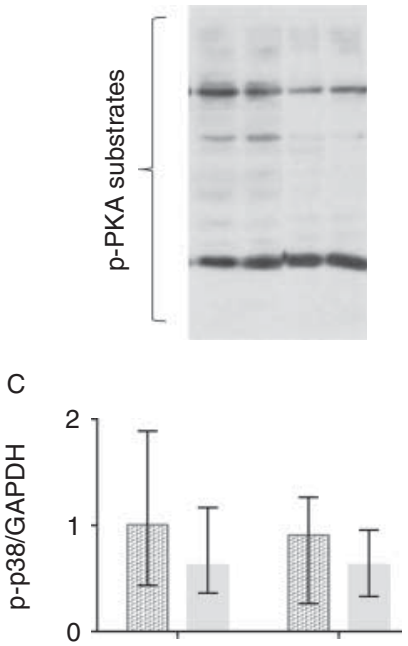

E
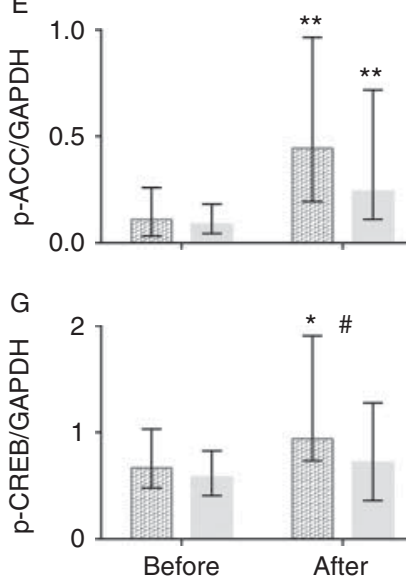

Figure 4

(A) The representative immunoblots and phosphorylation levels of (B)

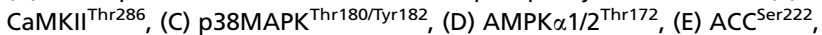
(F) PKA substrates, (G) and CREB1 ${ }^{\text {ser133 in } m \text {. vastus lateralis before and }}$ after acute high- and low-intensity cycling bouts ( $70 \%$ and $50 \% \dot{V}_{o_{2 m a x}}$ respectively). $0 \mathrm{~h}$ - the termination of the exercise. * and ** different from the initial level $(P<0.05$ and $P<0.01$ respectively); \# and \#\# different between intensities $(P<0.05$ and $P<0.01$, respectively). Each value represents the median and interquartile range. 

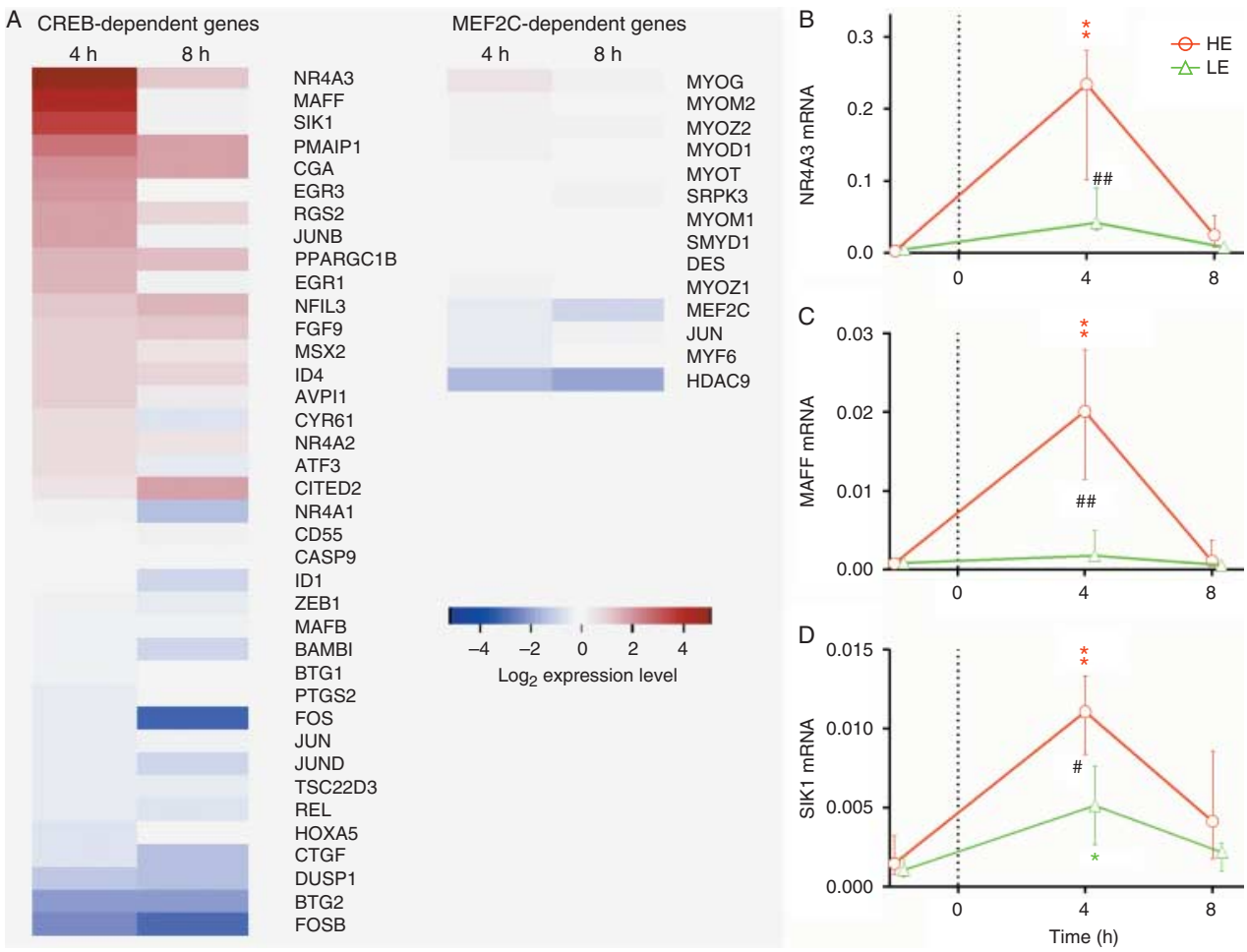

\section{Figure 5}

(A) Differential expression of CREB- and MEF2C-dependent genes in $m$. vastus lateralis before, $4 \mathrm{~h}$ and $8 \mathrm{~h}$ after acute high-intensity ( $70 \% \dot{V}_{2}{ }_{2 m a x}$ ) cycling bout. (B) The NR4A3, (C) MAFF, and (D) SIK1 expression in $m$. vastus lateralis before, $4 \mathrm{~h}$ and $8 \mathrm{~h}$ after acute high- and low-intensity cycling bouts ( $70 \%$ and $50 \% \dot{V}_{O_{2 m a x}}$ respectively). $0 \mathrm{~h}$ - the termination of exercise. * and ** different from the initial level $(P<0.05$ and $P<0.01$ respectively); \# and \#\# different between intensities $(P<0.05$ and $P<0.01$, respectively). Each value represents the median and interquartile range. the canonical and single alternative promoter, as described previously (Miura et al. 2008, Yoshioka et al. 2009). In addition to the PGC-1 $\alpha$ mRNA that contains 13 exons, we have identified one major alternative splice site between exons 6 and 7. This splice site produces transcripts from both transcription start sites (NT-PGC-1 $\alpha-a$ and $N T-P G C-1 \alpha-b$ mRNAs) in human (Ydfors et al. 2013) and mice (Wen et al. 2014) skeletal muscle, and plays a significant role in $P G C$ - $1 \alpha$-dependent regulation of angiogenesis (Thom et al. 2014). Importantly, only minor levels of other splice site variants were found (and not in all samples).

Multiple signaling pathways involved in contractile activity-mediated $P G C-1 \alpha$ gene expression via canonical promoter, such as elevations in cytoplasmic calcium, AMPK and p38 MAPK activation were discussed in a previous study (Zhang et al. 2014). In a number of studies, activation of AMPK (Rasmussen \& Winder 1997, Fujii et al. 2000, Chen et al. 2003, Sriwijitkamol et al. 2007, Egan et al. 2010), CaMKII (Rose et al. 2006, Egan et al. 2010), and stress-inducible p38 MAPK (Di Donato et al. 2014) positively associated with the intensity of exercise were shown in human skeletal muscle, while in one study (Egan et al. 2010) such association for p38 MAPK was not observed. We found that in endurance-trained human skeletal muscle, the canonical promoter $P G C-1 \alpha$ is constitutively expressed at rest and after exercise. The exercise-induced elevation in expression via the canonical promoter is small $(\sim 30 \%)$, and was similar after low or high intensity exercise. Previously, a model of intensitydependent regulation of $P G C-1 \alpha$ gene expression, via the canonical promoter, had been proposed in rodent skeletal muscle (Tadaishi et al. 2011). According to this model, both high intensity exercise and pharmacological activation of AMPK increased expression via the canonical promoter (Tadaishi et al. 2011, Wen et al. 2014). In our study, an intensity-dependent increase in $\mathrm{AMPK}^{\mathrm{Thr} 172}$ phosphorylation level had no association with $P G C-1 \alpha$ gene expression via the canonical promotor. A possible explanation for this finding is that in endurance-trained human skeletal muscle, expression via the canonical promoter at rest is close to maximal level; exercise-induced

Published by Bioscientifica Ltd. 
increases in AMPK activity therefore have little effect on expression via the promoter. In our study, activation of AMPK after HE might be associated with high AMP/ATP ratio and/or low post-exercise muscle glycogen level (Richter \& Ruderman 2009), both changes being a result either of higher intensity itself or recruitment of highthreshold fibres (Kristensen et al. 2015). Expression via the canonical promoter may also be regulated by the kinases p38 MAPK $^{\text {Thr180/Tyr182 }}$ and CaMKII ${ }^{\text {Thr286, through }}$ activation of MEF2C (McGee \& Hargreaves 2004) and CREB1-related protein, activating transcription factor 2 (ATF2) (Akimoto et al. 2005, Wright et al. 2007). Our study did not reveal exercise-induced changes in phosphorylation levels of p38 MAPK $^{\text {Thr180/Tyr182 }}$ and CaMKII ${ }^{\text {Thr286 }}$. Lack of exercise-induced increase of p38 MAPK $^{\text {Thr180/Tyr182 }}$ phosphorylation might be associated with fitness level of subjects. Indeed, the increase of post-exercise p38 MAPK $^{\text {Thr180/Tyr182 }}$ phosphorylation level was blunted in skeletal muscle adapted to endurance training in comparison to untrained muscle exercising with the same relative intensity (Coffey et al. 2006). On the other hand, the activity and phosphorylation level of $\mathrm{CaMKII}^{\mathrm{Thr} 286}$ rapidly increased just after initiation of dynamic muscle contraction (Rose et al. 2006). It is possible, that $\mathrm{CaMKII}^{\mathrm{Th} 286}$ phosphorylation level rapidly decreases just after termination of exercise, which partially explains the lack of exercise-induced increase of $\mathrm{CaMKII}^{\mathrm{Thr} 286}$ phosphorylation in the present study.

We found that expression of the $P G C-1 \alpha$ gene via the alternative promoter was markedly increased after both LE and HE sessions; post-exercise expression level via this promoter was threefold higher than via the canonical promoter, and was closely associated with exercise intensity. These findings are in agreement with previous studies in mice (Tadaishi et al. 2011, Wen et al. 2014). Expression via the alternative promoter is associated with exercise-induced metabolic stress (Norrbom et al. 2011) and with activation of the $\beta 2$-adrenergic receptor-cAMPPKA-CREB1 pathway (Miura et al. 2008, Yoshioka et al. 2009, Chinsomboon et al. 2009, Tadaishi et al. 2011, Wen et al. 2014). An earlier study demonstrated endurance exercise intensity-dependent increase of cAMP level in rat skeletal muscle (Goldfarb et al. 1989), but another study found no changes in post-exercise cAMP level in skeletal muscle of rats acclimatized to treadmill running (Sheldon et al. 1993). We did not find increase of phosphorylation level of PKA substrates (i.e. a marker of PKA activity) after both HE and LE. CREB1 can increase transcriptional activity in response to diverse stimuli (Shaywitz \& Greenberg 1999), including phosphorylation by AMPK
(Thomson et al. 2008). Aminoimidazole carboxamide ribonucleotide (AICAR) treatment in human myoblasts (Norrbom et al. 2011) and mice (Wen et al. 2014) revealed a role for AMPK in regulation of expression via the alternative promoter. However, another myoblast study (Yoshioka et al. 2009) and investigations in isolated rat muscle (Tadaishi et al. 2011) did not confirm this finding. In our study, theoretically, both PKA and AMPK as well as other stimuli may have roles in intensity-dependent increases in CREB1 ${ }^{\text {Ser133 }}$ phosphorylation levels and expression of CREB1-dependent genes.

The $P G C-1 \alpha$ canonical promoter region contains one conservative CRE-binding (palindromic) site for CREB1 and two binding sites for MEF2C (Esterbauer et al. 1999). Using high-throughput RNA-seq analysis, we found no changes in MEF2C-dependent gene expression. However, expression of CREB1-dependent genes was increased after high-intensity exercise session, which confirmed CREB1 activation. Moreover, the CREB1 target genes, NR4A3, MAFF and SIK1, showed expression that depended on intensity of exercise, similar to CREB1 $1^{\text {Ser133 }}$ phosphorylation levels. We speculate that, at rest, low concentrations of phosphorylated CREB1 $1^{\text {Ser133 }}$ are sufficient to induce near-maximal expression via the canonical promoter. Therefore, exercise-induced activation of CREB1 has a low impact on regulation of expression via the canonical promoter. The $P G C-1 \alpha$ alternative promoter region has a conservative CRE-binding site with a single nucleotide substitution (variant site) (Tadaishi et al. 2011). The variant site is functional but has a lower affinity for transcription factors, compared with the palindromic site (Heckert et al. 1996). This probably explains why expression via the alternative promoter, in resting muscle, is very low. Thus, exercise intensity-dependent increases in CREB $1^{\text {Ser133 }}$ phosphorylation levels may be sufficient to stimulate expression via the alternative promoter.

A previous study showed that the variant CRE-binding site in promoter of human $\alpha$ subunit gene depends more heavily on the upstream elements than a promoter with palindromic CRE (Heckert et al. 1996). The muscle-specific transcription factors, MyoD and MRF4, transactivate the alternative promoter in $P G C-1 \alpha$ gene in myoblasts through interaction with a proximal E-box motif (Yoshioka et al. 2009). It is possible that in our study these transcription factors play a role in the intensitydependent regulation of expression via the alternative promoter. Moreover, we cannot ignore the possibility that regulation of transcription via the alternative promoter is sensitive to other CREB1-related transcription factors,

Published by Bioscientifica Ltd. 
as well as to CREB1-dependent coactivators and repressors (Altarejos \& Montminy 2011).

In conclusion, this study has demonstrated that during post-exercise recovery, endurance-trained human skeletal muscle expresses the $P G C-1 \alpha$ gene via two promoters only. Constitutive expression occurs via the canonical promoter, independent of exercise intensity and AMPK $^{\text {Thr172 }}$ phosphorylation level. Expression of $P G C-1 \alpha-b$ mRNA, via the alternative promoter, is markedly increased only after exercise and has a greater contribution to the increase of total PGC-1 $\alpha$ mRNA compared to mRNA expression, via the canonical promoter. This post-exercise $P G C-1 \alpha-b$ mRNA expression is highly dependent on the intensity of exercise. There is an apparent association between expression via the alternative promoter and activation of CREB1. Clarification of the molecular mechanisms underlying $P G C-1 \alpha$ gene expression in human skeletal muscle may provide an opportunity to control the expression of different isoforms through varying exercise patterns, and/or through pharmacological interventions. These could be important strategies for optimization of endurance training as well as for treating patients with various diseases such as diabetes mellitus and metabolic syndrome.

\section{Supplementary data}

This is linked to the online version of the paper at http://dx.doi.org/10.1530/ JME-15-0150.

\section{Declaration of interest}

The authors declare that there is no conflict of interest that could be perceived as prejudicing the impartiality of the research reported.

\section{Funding}

This work was supported by the Russian Science Foundation (grant number 14-15-00768).

\section{Author contribution statement}

$D P$ and $O V$ designed the studies. D P, E L, T V, and N K conducted the experiments. D P, E L, T V, N K, and P M analysed the results. D $P$, and $\mathrm{O} V$ wrote the manuscript and all authors approved the final version of the manuscript.

\section{Acknowledgements}

The authors thank PhD Maria Logacheva (MV Lomonosov Moscow State University) for performing RNA sequencing and Dr Dmitriy Perfilov (Institute of Biomedical Problems, Russian Academy of Sciences, Moscow) for tissue acquisition.

\section{References}

Akimoto T, Pohnert SC, Li P, Zhang M, Gumbs C, Rosenberg PB, Williams RS \& Yan Z 2005 Exercise stimulates Pgc- $1 \alpha$ transcription in skeletal muscle through activation of the p38 MAPK pathway. Journal of Biological Chemistry 280 19587-19593. (doi:10.1074/jbc.M408862200)

Altarejos JY \& Montminy M 2011 CREB and the CRTC co-activators: sensors for hormonal and metabolic signals. Nature Reviews. Molecular Cell Biology 12 141-151. (doi:10.1038/nrm3072)

Anders S \& Huber W 2010 Differential expression analysis for sequence count data. Genome Biology 11 R106. (doi:10.1186/gb-2010-11-10-r106)

Chang JS, Fernand V, Zhang Y, Shin J, Jun HJ, Joshi Y \& Gettys TW 2012 NT-PGC- $1 \alpha$ protein is sufficient to link $\beta 3$-adrenergic receptor activation to transcriptional and physiological components of adaptive thermogenesis. Journal of Biological Chemistry 287 9100-9111. (doi:10.1074/jbc.M111.320200)

Chen ZP, Stephens TJ, Murthy S, Canny BJ, Hargreaves M, Witters LA, Kemp BE \& McConell GK 2003 Effect of exercise intensity on skeletal muscle AMPK signaling in humans. Diabetes 52 2205-2212. (doi:10.2337/diabetes.52.9.2205)

Chinsomboon J, Ruas J, Gupta RK, Thom R, Shoag J, Rowe GC, Sawada N, Raghuram S \& Arany Z 2009 The transcriptional coactivator PGC-1 $\alpha$ mediates exercise-induced angiogenesis in skeletal muscle. PNAS 106 21401-21406. (doi:10.1073/pnas.0909131106)

Coffey VG, Zhong Z, Shield A, Canny BJ, Chibalin AV, Zierath JR \& Hawley JA 2006 Early signaling responses to divergent exercise stimuli in skeletal muscle from well-trained humans. FASEB Journal 20 190-192. (doi:10.1096/fj.05-4809fje)

Di Donato DM, West DW, Churchward-Venne TA, Breen L, Baker SK \& Phillips SM 2014 Influence of aerobic exercise intensity on myofibrillar and mitochondrial protein synthesis in young men during early and late postexercise recovery. American Journal of Physiology. Endocrinology and Metabolism 306 E1025-E1032. (doi:10.1152/ajpendo.00487.2013)

Egan B, Carson BP, Garcia-Roves PM, Chibalin AV, Sarsfield FM, Barron N, McCaffrey N, Moyna NM, Zierath JR \& O'Gorman DJ 2010 Exercise intensity-dependent regulation of peroxisome proliferator-activated receptor coactivator-1 mRNA abundance is associated with differential activation of upstream signalling kinases in human skeletal muscle. Journal of Physiology 588 1779-1790. (doi:10.1113/jphysiol.2010.188011)

Esterbauer H, Oberkofler H, Krempler F \& Patsch W 1999 Human peroxisome proliferator activated receptor $\gamma$ coactivator 1 (PPARGC1) gene: cDNA sequence, genomic organization, chromosomal localization, and tissue expression. Genomics 62 98-102. (doi:10.1006/geno. 1999.5977)

Felder TK, Soyal SM, Oberkofler H, Hahne P, Auer S, Weiss R, Gadermaier G, Miller K, Krempler F, Esterbauer H et al. 2011 Characterization of novel peroxisome proliferator-activated receptor $\gamma$ coactivator- $1 \alpha$ (PGC- $1 \alpha$ ) isoform in human liver. Journal of Biological Chemistry 286 42923-42936. (doi:10.1074/jbc.M111.227496)

Fujii N, Hayashi T, Hirshman MF, Smith JT, Habinowski SA, Kaijser L, Mu J, Ljungqvist O, Birnbaum MJ, Witters LA et al. 2000 Exercise induces isoform-specific increase in 5'AMP-activated protein kinase activity in human skeletal muscle. Biochemical and Biophysical Research Communications 273 1150-1155. (doi:10.1006/bbrc.2000.3073)

Goldfarb AH, Bruno JF \& Buckenmeyer PJ 1989 Intensity and duration of exercise effects on skeletal muscle cAMP, phosphorylase, and glycogen. Journal of Applied Physiology 66 190-194.

Hayot M, Michaud A, Koechlin C, Caron MA, LeBlanc P, Prefaut C \& Maltais F 2005 Skeletal muscle microbiopsy: a validation study of a minimally invasive technique. European Respiratory Journal 25 431-440. (doi:10.1183/09031936.05.00053404)

Heckert LL, Schultz K \& Nilson JH 1996 The cAMP response elements of the $\alpha$ subunit gene bind similar proteins in trophoblasts and gonadotropes but have distinct functional sequence requirements. Journal of Biological Chemistry 271 31650-31656. (doi:10.1074/jbc.271.49.31650) 
Kristensen DE, Albers PH, Prats C, Baba O, Birk JB \& Wojtaszewski JF 2015 Human muscle fibre type-specific regulation of AMPK and downstream targets by exercise. Journal of Physiology 593 2053-2069. (doi:10.1113/ jphysiol.2014.283267)

McGee SL \& Hargreaves M 2004 Exercise and myocyte enhancer factor 2 regulation in human skeletal muscle. Diabetes 53 1208-1214. (doi:10.2337/diabetes.53.5.1208)

Miura S, Kai Y, Kamei Y \& Ezaki O 2008 Isoform-specific increases in murine skeletal muscle peroxisome proliferator-activated receptor- $\gamma$ coactivator- $1 \alpha$ (PGC-1 $\alpha$ ) mRNA in response to $\beta 2$-adrenergic receptor activation and exercise. Endocrinology 149 4527-4533. (doi:10.1210/en. 2008-0466)

Norrbom J, Sallstedt EK, Fischer H, Sundberg CJ, Rundqvist H \& Gustafsson T 2011 Alternative splice variant PGC- $1 \alpha-b$ is strongly induced by exercise in human skeletal muscle. American Journal of Physiology. Endocrinology and Metabolism 301 E1092-E1098. (doi:10.1152/ajpendo.00119.2011)

Olesen J, Kiilerich K \& Pilegaard H 2010 PGC-1 $\alpha$-mediated adaptations in skeletal muscle. Pflügers Archiv 460 153-162. (doi:10.1007/s00424-0100834-0)

Perry CG, Lally J, Holloway GP, Heigenhauser GJ, Bonen A \& Spriet LL 2010 Repeated transient mRNA bursts precede increases in transcriptional and mitochondrial proteins during training in human skeletal muscle. Journal of Physiology 588 4795-4810. (doi:10.1113/jphysiol.2010. 199448)

Popov DV, Bachinin AV, Lysenko EA, Miller TF \& Vinogradova OL 2014 Exercise-induced expression of peroxisome proliferator-activated receptor $\gamma$ coactivator- $1 \alpha$ isoforms in skeletal muscle of endurancetrained males. Journal of Physiological Sciences 64 317-323. (doi:10.1007/ s12576-014-0321-z)

Popov DV, Lysenko EA, Kuzmin Vinogr IV, adova OL \& Grigoriev AI 2015 Regulation of PGC-1a Isoform Expression in Skeletal Muscles. Acta Naturae 7 48-59.

Rasmussen BB \& Winder WW 1997 Effect of exercise intensity on skeletal muscle malonyl-CoA and acetyl-CoA carboxylase. Journal of Applied Physiology 83 1104-1109.

Richter EA \& Ruderman NB 2009 AMPK and the biochemistry of exercise: implications for human health and disease. Biochemical Journal $\mathbf{4 1 8}$ 261-275. (doi:10.1042/BJ20082055)

Rose AJ, Kiens B \& Richter EA $2006 \mathrm{Ca}^{2+}$-calmodulin-dependent protein kinase expression and signalling in skeletal muscle during exercise. Journal of Physiology 574 889-903. (doi:10.1113/jphysiol.2006.111757)

Ruas JL, White JP, Rao RR, Kleiner S, Brannan KT, Harrison BC, Greene NP, $\mathrm{Wu}$ J, Estall JL, Irving BA et al. 2012 A PGC-1 $\alpha$ isoform induced by resistance training regulates skeletal muscle hypertrophy. Cell $\mathbf{1 5 1}$ 1319-1331. (doi:10.1016/j.cell.2012.10.050)

Shaywitz AJ \& Greenberg ME 1999 CREB: a stimulus-induced transcription factor activated by a diverse array of extracellular signals. Annual Review of Biochemistry 68 821-861. (doi:10.1146/annurev.biochem.68.1.821)

Sheldon A, Booth FW \& Kirby CR 1993 cAMP levels in fast- and slow-twitch skeletal muscle after an acute bout of aerobic exercise. American Journal of Physiology 264 C1500-C1504.

Soyal SM, Felder TK, Auer S, Hahne P, Oberkofler H, Witting A, Paulmichl M, Landwehrmeyer GB, Weydt P \& Patsch W 2012 A greatly extended PPARGC1A genomic locus encodes several new brain-specific isoforms and influences Huntington disease age of onset. Human Molecular Genetics 21 3461-3473. (doi:10.1093/hmg/dds177)

Sriwijitkamol A, Coletta DK, Wajcberg E, Balbontin GB, Reyna SM, Barrientes J, Eagan PA, Jenkinson CP, Cersosimo E, DeFronzo RA et al. 2007 Effect of acute exercise on AMPK signaling in skeletal muscle of subjects with type 2 diabetes: a time-course and dose-response study. Diabetes 56 836-848. (doi:10.2337/db06-1119)

Tadaishi M, Miura S, Kai Y, Kawasaki E, Koshinaka K, Kawanaka K, Nagata J, Oishi Y \& Ezaki O 2011 Effect of exercise intensity and AICAR on isoform-specific expressions of murine skeletal muscle PGC- $1 \alpha$ mRNA: a role of $\beta(2)$-adrenergic receptor activation. American Journal of Physiology. Endocrinology and Metabolism 300 E341-E349. (doi:10.1152/ ajpendo.00400.2010)

Thom R, Rowe GC, Jang C, Safdar A \& Arany Z 2014 Hypoxic induction of vascular endothelial growth factor (VEGF) and angiogenesis in muscle by truncated peroxisome proliferator-activated receptor $\gamma$ coactivator (PGC)-1 $\alpha$. Journal of Biological Chemistry 289 8810-8817. (doi:10.1074/ jbc.M114.554394)

Thomson DM, Herway ST, Fillmore N, Kim H, Brown JD, Barrow JR \& Winder WW 2008 AMP-activated protein kinase phosphorylates transcription factors of the CREB family. Journal of Applied Physiology 104 429-438. (doi:10.1152/japplphysiol.00900.2007)

Thorvaldsdottir H, Robinson JT \& Mesirov JP 2013 Integrative genomics viewer (IGV): high-performance genomics data visualization and exploration. Briefings in Bioinformatics 14 178-192. (doi:10.1093/bib/ bbs017)

Wen X, Wu J, Chang JS, Zhang P, Wang J, Zhang Y, Gettys TW \& Zhang Y 2014 Effect of exercise intensity on isoform-specific expressions of NT-PGC-1 $\alpha$ mRNA in mouse skeletal muscle. BioMed Research International 2014 402175. (doi:10.1155/2014/402175)

Wright DC, Geiger PC, Han DH, Jones TE \& Holloszy JO 2007 Calcium induces increases in peroxisome proliferator-activated receptor $\gamma$ coactivator- $1 \alpha$ and mitochondrial biogenesis by a pathway leading to p38 mitogen-activated protein kinase activation. Journal of Biological Chemistry 282 18793-18799. (doi:10.1074/jbc.M611252200)

Ydfors M, Fischer H, Mascher H, Blomstrand E, Norrbom J \& Gustafsson T 2013 The truncated splice variants, NT-PGC- $1 \alpha$ and PGC- $1 \alpha 4$, increase with both endurance and resistance exercise in human skeletal muscle. Physiological Reports 1 e00140. (doi:10.1002/phy2.140)

Yoshioka T, Inagaki K, Noguchi T, Sakai M, Ogawa W, Hosooka T, Iguchi H, Watanabe E, Matsuki Y, Hiramatsu R et al. 2009 Identification and characterization of an alternative promoter of the human PGC-1 $\alpha$ gene. Biochemical and Biophysical Research Communications 381 537-543. (doi:10.1016/j.bbrc.2009.02.077)

Zhang Y, Huypens P, Adamson AW, Chang JS, Henagan TM, Boudreau A, Lenard NR, Burk D, Klein J, Perwitz N et al. 2009 Alternative mRNA splicing produces a novel biologically active short isoform of PGC- $1 \alpha$. Journal of Biological Chemistry 284 32813-32826. (doi:10.1074/jbc. M109.037556)

Zhang Y, Uguccioni G, Ljubicic V, Irrcher I, Iqbal S, Singh K, Ding S \& Hood DA 2014 Multiple signaling pathways regulate contractile activity-mediated PGC- $1 \alpha$ gene expression and activity in skeletal muscle cells. Physiological Reports 2 e12008. (doi:10.14814/phy2.12008)

Received in final form 22 July 2015

Accepted 19 August 2015

Accepted Preprint published online 20 August 2015 http://jme.endocrinology-journals.org

DOI: 10.1530/JME-15-0150
() 2015 Society for Endocrinology Printed in Great Britain
Published by Bioscientifica Ltd. 